\title{
Does a one-week health program promote well-being among caregiving parents? A quasiexperimental intervention study in Germany
}

Christian Hetzel ( $\sim$ hetzel@iqpr.de )

Insitute for Quality Assurance in Prevention and Rehabilitation https://orcid.org/0000-0002-4767-8244

\section{Torsten Alles}

Insitute for Quality Assurance in Prevention and Rehabilitation

\section{Michael Holzer}

Social Insurance for Agriculture, Forestry and Horticulture

\section{Erich Koch}

Social Insurance for Agriculture, Forestry and Horticulture

\section{Ingo Froböse}

The Institute of Movement Therapy and Movement-oriented Prevention and Rehabilitation at the German Sport University Cologne

\section{Research Article}

Keywords: well-being, mental health, informal care, caregiving parents, panel regression

Posted Date: June 23rd, 2021

DOI: https://doi.org/10.21203/rs.3.rs-252444/v1

License: (a) (i) This work is licensed under a Creative Commons Attribution 4.0 International License. Read Full License

Version of Record: A version of this preprint was published at Journal of Public Health on January 15th, 2022. See the published version at https://doi.org/10.1007/s10389-021-01671-2. 


\section{Abstract}

Aim: The effect of a legally funded, one-week health program offered by the Social Insurance for Agriculture, Forestry and Horticulture (SVLFG) on the well-being of the participating caregiving parents is determined. Secondary outcome measures are stress and behavior theory-based characteristics.

Subject and methods: In a controlled panel study (intervention group $n=23$, comparison group $n=33$, allocation not randomized) the WHO-5 index and other measures were collected at several measurement points. Statistical methods are fixed effects panel regressions under control of time-varying characteristics (external conditions, period effects).

Results: At the start of the intervention 70 percent of the intervention group are at the threshold of clinically relevant depressiveness. After a very clear initial effect, the level remains above the baseline level for up to 15 weeks after the intervention (under stable conditions). A sinking below the initial level is prevented until at least 26 weeks even with significantly increasing external conditions. The main drivers appear to be sustained increases in acceptance of the care situation, institutional support, and recreational behavior.

Conclusion: In view of the high initial burden of the participants, the sustainability of the prevention-oriented intervention is considerable. The intervention is unique for the social insurance system in Germany. The design allows a causal interpretation despite the small number of cases.

\section{Background}

It is evident that informal caregivers are a mainstay of care and a vulnerable group. They are exposed to numerous stresses with negative health consequences (Harris et al. 2020, Maguire et al. 2019, Calvo-Perxas et al. 2018, Verbakel et al. 2017, Berglund et al. 2015). However, studies are largely limited to the field of adult or elderly care, especially for dementia. Little research has been conducted on the consequences for the families of children and adolescents needing care (Mauz et al. 2019, Cousino and Hazen 2013).

In Germany, according to the Social Code Book XI, people are considered to be in need of care if they cannot (permanently) compensate or cope independently with their physical, cognitive or mental impairments or health-related burdens or demands ( $§ 14$ Social Code Book XI). In 2019, about 4 million people and about 163,000 of them children under the age of 15 were recognized as needing long-term care (BMG 2020). Longterm care insurance provides various forms of assistance for people in need of care and their caregivers. On this basis, it can be determined that 77 percent of people in need of care are currently cared for at home supported by outpatient services if necessary. In the green sector (the entirety of the agricultural, forestry and horticultural sectors), among whose members this study was conducted, the share is even significantly higher at 92 percent (Hetzel 2020). 98 percent of the children (0 to 14 years) and 91 percent of the adolescents (15 to 19 years) in need of care are cared for at home (BMG 2020).

What characterizes home care for these children and adolescents?

- Lack of information and recognition: A survey of parents with chronically ill children in Germany showed that around 78 percent of parents had no knowledge of existing family support services and only one 
third of respondents were aware of early intervention services. Almost 60 percent of parents state that no one understands the tremendous burdens they have to cope with (Vonneilich, Lüdecke \& Kofahl 2016).

- Lack of acceptance of the care situation: The diagnosis of the need for care of one's own child is to be regarded as a critical life event, the processing of which causes difficulties for many parents (CantwellBartl and Tibballs 2015).

- Consequential burdens: The already high care-related burdens lead to burdens on the family system, to professional and financial losses and to restrictions in leisure time (Dehn et al. 2014, Nehring et al. 2015). Employment rate and equivalence income are significantly lower in parents of children with disabilities than in parents of healthy children (Vonneilich, Lüdecke \& Kofahl 2016).

- Special problems in the life course: Puberty and adolescence are of particular importance. During this time, adolescents are detached from their parents and the necessary therapeutic measures must increasingly be carried out on their own responsibility. During the transition to adult medical care at the age of 18 , breaks in care often occur, i.e. necessary therapies are not continued seamlessly.

Supply deficits: In everyday care, there is a glaring gap between desire and reality with regard to the use of support services. Based on a survey of insured persons, only just under 13 percent of young people in need of care made use of day care and 9 percent of short-term care. But about twice as many families would like to use these services in each case. The reasons given by the majority are a lack of age- and illness-specific offerings, as well as excessively long waiting times and too great a distance. It is problematic that nursing facilities are predominantly specialized in geriatric care (Rothgang et al. 2017). Existing multi-day offers are unspecific. Effectiveness and sustainability have been demonstrated for mother/father-child cures (Barre and Epping 2018). However, these measures are not specifically targeted at parents whose children are chronically ill or disabled and are also therapeutically oriented. Preventive and multi-day programs for family caregivers are the exception in Germany. Only the Social Insurance for Agriculture, Forestry and Horticulture (SVLFG) (Hetzel et al 2016) and the BARMER health insurance (Hetzel et al. 2017, 2018) regularly offer such programs. The Techniker health insurance had a similar but projected offer in the past (Dlugosch and Mücke 2006). These offers show positive effects on mental health, but are or were also not specifically aimed at caring parents. However, experience shows that there is a clear need for precisely this target group, because caring parents sometimes feel like a "fifth wheel" and "out of place" among carers of adults or older people.

These conditions lead to impaired health in caregiving parents. Parents of children and adolescents with severe disabilities often suffer from anxiety, frustration, guilt, social isolation, and sleep disturbances (Ausserhofer et al. 2009), as well as depression (Ausserhofer et al. 2009, Brehaut et al. 2011) and reduced quality of life (Seliner et al. 2016). More than one-third of surveyed parents of care-intensive children (Vonneilich, Lüdecke \& Kofahl 2016) described their overall health as "less than good" or "poor". The older the children and the lower the supply intensity, the better the health status of the parents. A downward spiral occurs because younger children with high care intensity are also associated with the highest social and financial burdens in the family.

Therefore, SVLFG has decided to specifically target its well-established training and recovery week for informal caregivers to caregiving parents. The primary endpoint of the intervention study is the well-being of the caregiving parents. Secondary outcome measures are theory based attitudinal and behavioral measures to capture possible mechanisms related to well-being. 


\section{Material \& Methods}

\section{Intervention}

The intervention entitled "Caring Parents" is an inpatient and legally funded (SGB XI) group event for caring parents with the aim of health promotion and prevention. It lasts eight days and is designed for up to 15 caregiving parents (not including the cared-for children). If needed, the SVLFG will assist in organizing substitute care under statutory benefits. The venue is a rehabilitation center in combination with a hotel in Bavaria, Germany. Participants pay a total of 99 euros for accommodation and meals.

In the care course ( $4 \times 180 \mathrm{~min})$, the participants' own care situation is analyzed with regard to care-related and psychological aspects. Specific needs of the participants are qualitatively determined and integrated into the program as far as possible. In particular, the parts of the course that are related to nursing care take place in a practical manner and with the use of aids. As part of the care course, a care advisor provides information on statutory benefit entitlements and on offers of support and relief. The aim of the psychological aspects is to build up personal resources and successfully cope with the stressors associated with nursing care. Offers on relaxation techniques, exercise for an individual home program and leisure activities promote the development of health-promoting behavior and allow recovery effects to be expected. The individual units are led by specialists (psychology $240 \mathrm{~min}$, exercise $240 \mathrm{~min}$ ) who are also available for individual discussions. The latter applies in particular to the psychologist in order to facilitate a low-threshold initial contact in the event of a possible therapeutic need. Other components include a lecture by a safety advisor on accident prevention (90 $\mathrm{min}$ ) and a joint visit to a support facility, including a discussion with the management (180 $\mathrm{min})$. There are free spaces between the units for an informal exchange of experiences.

Behavioral theory aims to promote care-relieving behavior (e.g., use of support services) and healthpromoting behavior (e.g., exercise, relaxation, or hobbies) (Prochaska et al. 1994, Kelly and Barker 2016). Various behavior change techniques are used for this purpose (Michie et al. 2011). Central to this are the promotion of model learning within the group, consideration of past successes, and barrier identification. Basis for action for the psychological parts are especially stress management concepts. The theoretical background is a stress theoretical model with nursing-related conceptualization (Perlin et al. 1990, Sörensen et al. 2006, Clark and Diamond 2006). Primary stressors result directly from tasks and demands associated

with nursing. They affect other areas of life, especially work, family and leisure (secondary stressors). At both levels, there are objective and subjective stressors, respectively. The end point is the impairment of the physical and mental health of the caregiver. The entire chain of effects is influenced in particular by coping strategies and experienced support as well as by contextual conditions (e.g. need for help, finances).

\section{Design}

In a controlled prospective panel study, data are collected at several measurement time points so that primarily intra-individual changes can be recorded in a temporal sequence. Allocation into intervention group (IG) and comparison group (CG) is non-randomized (quasi-experimental design), i.e., group membership is self-selected. The CG did not receive any special intervention beyond the services established in individual everyday life. 
The two groups were recruited via personal letters from the SVLFG insured population, the IG additionally via approach by SVLFG personnel and via public relations of the SVLFG. Inclusion criteria for both groups were residence in Bavaria, a child born in 1975 or later and recognized as needing care, and a caregiving parent or the child insured with SVLFG. Parents of the CG had to rate the intervention as "interesting" - the assumption was to achieve a similarity in structure to the IG.

A scientifically robust overall instrument suitable for the present research question is not available (Lefranc et al. 2017), so that proven subinstruments and in-house developments were used. The primary outcome measure is well-being, operationalized with the WHO-5 Well Being Index (Bech 2012, Topp et al. 2015), an internationally used screening instrument for depression, among other things, which is also recommended for follow-up studies (Topp et al. 2015). The test quality is rated as excellent and there are norm values for Germany from 2004 (Brähler et al. 2007). The Index has five questions, which are part of the definition of major depression or a depressive episode, with six response levels each. A sum score of up to and including 52 raises suspicion of a depressive illness. It should be emphasized that this threshold at most indicates the presence of a depressive episode, but is not an exact clinical individual diagnosis.

The following secondary outcome measures and time-varying confounding variables are collected (number of items / number of response levels):

- Subjective burden of caring parents (11/4) (Dehn et al. 2014)

- Acceptance of care situation (4/5), Institutional support (3/5), Social support (3/5) (Hetzel et al. 2019)

Recreational behavior (3/5), Care-related behavior (3/5), Change in external conditions (3/11), based on (Hetzel et al. 2016, 2017)

All scales are linearly normalized from 0 to 100. The higher the value, the more frequently the behaviors are implemented or the more clearly the agreement. In addition, in the green sector, from which the target group originates, the summer period is characterized by above-average work intensity and thus a potential period effect. Therefore, the calendar week of the response was recorded and dichotomized as the summer period (weeks 18-44).

For the IG, at least 2 measurement time points were planned to take place before the intervention (about 2 months and immediately before the start) and 4 more after the intervention (immediately after and after 1, 3 and 6 months). For the CG, 3 measurement time points were planned (0, 3, and 6 months). Data were collected in writing by questionnaire, with a one-time reminder if no response was received. The calendar week of the information in the questionnaire was recorded and then the class mean per measurement time point was calculated. The actual measurement time points were on average 5, 15 and 26 weeks after the end of the intervention.

\section{Statistics}

Panel regression methods are used that allow causal interpretation despite the non-experimental design (Brüderl and Ludwig 2015, Allison 2009). Fixed effects (FE) estimators have the potential to implicitly control for time-constant unobserved heterogeneity. This is of paramount importance given the self-selection into the intervention and the bias this is very likely to introduce. In addition, the care situations are often quite stable 
over time, especially in the care of disabled children. Last but not least, the sample size is small, so the ability to control for confounding variables is limited in number. With FE estimators, the development of a person's outcome measure after the intervention is compared with the development before the intervention (withinestimation). The comparison group serves "only" to control for intervention-independent effects on the outcome measures - in this case, the summer period and changes in external conditions - and not for direct comparison (between-estimation). Thus, the lack of randomization is compensated for by the prior measurements. For the analyses using panel regression, the R package "plm" is used (Croissant and Millo 2008). Standard errors are estimated panel-robustly.

\section{Results}

\section{Sample}

In the IG, 3 events (March, April, and August 2019) were implemented with a total of 23 individuals (7,10, and 6). In the IG, all persons participated at the measurement time points from the beginning of the intervention. Only 15 persons participated in the measurement before the intervention, because for the first event, no further before measurement was possible due to organizational reasons and because one person registered at short notice for one of the following events. In the CG, 33 persons participated initially and 26 persons each after 15 and 26 weeks, respectively.

Table 1 shows the structure and baseline levels of the two groups. The structures and baseline levels of the outcome measures are quite similar in both groups. Statistical comparisons are omitted in view of the selection bias. 
Table 1

Structure and baseline levels of the groups

\begin{tabular}{|c|c|c|c|}
\hline & & $\begin{array}{l}\text { CG }(n \\
=33)\end{array}$ & $\begin{array}{l}\text { IG }(n= \\
23)\end{array}$ \\
\hline \multirow[t]{2}{*}{ Participant } & Mother & $94 \%$ & $83 \%$ \\
\hline & Father & $6 \%$ & $17 \%$ \\
\hline \multirow[t]{4}{*}{ Who does your child live with? } & Mother and father & $82 \%$ & $91 \%$ \\
\hline & Mother & $3 \%$ & $4 \%$ \\
\hline & Father & $0 \%$ & $0 \%$ \\
\hline & Others (e.g. foster parents) & $15 \%$ & $4 \%$ \\
\hline \multirow[t]{4}{*}{ Caregiver age (years) } & Up to 40 & $3 \%$ & $9 \%$ \\
\hline & $41-50$ & $42 \%$ & $17 \%$ \\
\hline & $51-65$ & $48 \%$ & $43 \%$ \\
\hline & 66 and older & $6 \%$ & $30 \%$ \\
\hline \multirow[t]{4}{*}{ Child age (years) } & Up to 12 & $24 \%$ & $13 \%$ \\
\hline & $13-17$ & $30 \%$ & $22 \%$ \\
\hline & $18-30$ & $30 \%$ & $30 \%$ \\
\hline & 31 and older & $15 \%$ & $35 \%$ \\
\hline \multirow[t]{2}{*}{ Does your child have siblings? } & No & $12 \%$ & $9 \%$ \\
\hline & Yes & $88 \%$ & $91 \%$ \\
\hline \multirow[t]{3}{*}{ Marital status } & Single parent & $3 \%$ & $0 \%$ \\
\hline & Living in partnership & $97 \%$ & $91 \%$ \\
\hline & Widowed & $0 \%$ & $9 \%$ \\
\hline \multirow[t]{2}{*}{ Do you live or work in a green sector business? } & No & $6 \%$ & $4 \%$ \\
\hline & Yes & $94 \%$ & $96 \%$ \\
\hline \multirow[t]{4}{*}{ Your vocational training? } & None & $3 \%$ & $4 \%$ \\
\hline & Semi-skilled & $3 \%$ & $0 \%$ \\
\hline & Apprenticeship, technical school & $70 \%$ & $83 \%$ \\
\hline & $\begin{array}{l}\text { Master craftsman, technical } \\
\text { college, university }\end{array}$ & $24 \%$ & $13 \%$ \\
\hline \multicolumn{4}{|c|}{$\begin{array}{l}\text { Note: IG/CG = intervention/comparison group, baseline measures for IG is measurement time at } \\
\text { intervention start, a) if no, duration of care in years mean } 17.1 \text { years }(S D=11.5) \text { for IG and mean } 14.9 \\
\text { years }(S D=13.0) \text { for } C G \text {. }\end{array}$} \\
\hline
\end{tabular}




\begin{tabular}{|c|c|c|c|}
\hline & & $\begin{array}{l}\text { CG }(n \\
=33)\end{array}$ & $\begin{array}{l}\text { IG }(n= \\
23)\end{array}$ \\
\hline \multirow[t]{5}{*}{ Care level child } & 1 & $0 \%$ & $0 \%$ \\
\hline & 2 & $18 \%$ & $18 \%$ \\
\hline & 3 & $21 \%$ & $27 \%$ \\
\hline & 4 & $39 \%$ & $18 \%$ \\
\hline & 5 & $21 \%$ & $36 \%$ \\
\hline \multirow[t]{2}{*}{ Illness/disability since birth? } & $\mathrm{No}^{\mathrm{a})}$ & $15 \%$ & $30 \%$ \\
\hline & Yes & $85 \%$ & $70 \%$ \\
\hline \multirow{2}{*}{$\begin{array}{l}\text { Are you taking care of another person in need of } \\
\text { care? }\end{array}$} & No & $79 \%$ & $61 \%$ \\
\hline & Yes & $21 \%$ & $39 \%$ \\
\hline \multirow{2}{*}{$\begin{array}{l}\text { Have you ever attended a nursing class or } \\
\text { training? }\end{array}$} & No & $58 \%$ & $48 \%$ \\
\hline & Yes & $42 \%$ & $52 \%$ \\
\hline \multirow{2}{*}{$\begin{array}{l}\text { Have you ever participated in an SVLFG training } \\
\text { and recovery week? }\end{array}$} & No & $61 \%$ & $61 \%$ \\
\hline & Yes & $39 \%$ & $39 \%$ \\
\hline Well-being & Mean (SD) & $\begin{array}{l}40.2 \\
(19.7)\end{array}$ & $\begin{array}{l}45.0 \\
(21.6)\end{array}$ \\
\hline \multicolumn{2}{|l|}{ Subjective burden } & $\begin{array}{l}52.7 \\
(22.5)\end{array}$ & $\begin{array}{l}49.0 \\
(16.4)\end{array}$ \\
\hline \multicolumn{2}{|l|}{ Institutional support } & $\begin{array}{l}57.8 \\
(24.2)\end{array}$ & $\begin{array}{l}50.0 \\
(17.9)\end{array}$ \\
\hline \multicolumn{2}{|l|}{ Social recognition } & $\begin{array}{l}52.0 \\
(25.5)\end{array}$ & $\begin{array}{l}53.3 \\
(17.5)\end{array}$ \\
\hline \multicolumn{2}{|l|}{ Acceptance of care situation } & $\begin{array}{l}78.0 \\
(13.1)\end{array}$ & $\begin{array}{l}67.1 \\
(22.0)\end{array}$ \\
\hline \multicolumn{2}{|l|}{ Recreational behavior } & $\begin{array}{l}25.9 \\
(20.1)\end{array}$ & $\begin{array}{l}31.4 \\
(18.6)\end{array}$ \\
\hline \multicolumn{2}{|l|}{ Care-related behavior } & $\begin{array}{l}24.1 \\
(16.3)\end{array}$ & $\begin{array}{l}27.5 \\
(22.0)\end{array}$ \\
\hline \multicolumn{2}{|l|}{ External conditions } & $\begin{array}{l}29.3 \\
(22.2)\end{array}$ & $\begin{array}{l}32.1 \\
(20.8)\end{array}$ \\
\hline \multicolumn{4}{|c|}{$\begin{array}{l}\text { Note: IG/CG = intervention/comparison group, baseline measures for IG is measurement time at } \\
\text { intervention start, a) if no, duration of care in years mean } 17.1 \text { years }(S D=11.5) \text { for IG and mean } 14.9 \\
\text { years }(S D=13.0) \text { for } C G \text {. }\end{array}$} \\
\hline
\end{tabular}


The performance limitations of the children in need of care are broadly spread. In the IG (similarly the CG), 82 percent of the children have limitations in mood, concentration, behavior or interaction with others, 87 percent in motor skills and 78 percent in vision, hearing, smell or speech. 41 percent attend a special school and 27 percent attend a support center/residential home.

\section{Well-being}

Baseline level of well-being is shown in Table 1. For 70 percent of IG and for 73 percent of CG, the instrument's threshold indicates clinically relevant depressiveness.

Figure 1 shows the change in well-being over time compared with the pretest measurements. Under the condition of stable external conditions, the intervention promotes well-being very significantly at the end of the intervention (delta $=+33$ points). Thereafter, the effect flattens, but well-being is still significantly higher at 5 and 15 weeks than before the intervention began (delta $=+14$ and +15 points, respectively). After 26 weeks, the change from the baseline level still tends to be positive, but is no longer statistically significant (for values see Table 2, model 5). 
Table 2

Fixed effects models for well-being

\begin{tabular}{|c|c|c|c|c|c|c|c|c|c|c|}
\hline & \multicolumn{2}{|c|}{ model 1} & \multicolumn{2}{|c|}{ model 2} & \multicolumn{2}{|c|}{ model 3} & \multicolumn{2}{|c|}{ model 4} & \multicolumn{2}{|c|}{ model 5} \\
\hline & $\begin{array}{l}b \\
\text { (s.e.) }\end{array}$ & $p$ & $\begin{array}{l}b \\
\text { (s.e.) }\end{array}$ & $p$ & $\begin{array}{l}b \\
\text { (s.e.) }\end{array}$ & $p$ & $\begin{array}{l}b \\
\text { (s.e.) }\end{array}$ & $p$ & $\begin{array}{l}b \\
\text { (s.e.) }\end{array}$ & $p$ \\
\hline $\begin{array}{l}0 \text { weeks } \\
(\mathrm{m} 1)\end{array}$ & $\begin{array}{l}37.74 \\
(3.89)\end{array}$ & $\begin{array}{l}<.001 \\
0.00\end{array}$ & $\begin{array}{l}30.45 \\
(4.27)\end{array}$ & $\begin{array}{l}<.001 \\
0.00\end{array}$ & $\begin{array}{l}37.76 \\
(3.88)\end{array}$ & $\begin{array}{l}<.001 \\
0\end{array}$ & $\begin{array}{l}33.27 \\
(4.81)\end{array}$ & $\begin{array}{l}<.001 \\
0\end{array}$ & $\begin{array}{l}33.04 \\
(4.81)\end{array}$ & <. 001 \\
\hline $\begin{array}{l}5 \text { weeks } \\
(\mathrm{m} 2)\end{array}$ & $\begin{array}{l}10.72 \\
(3.89)\end{array}$ & 0.007 & $\begin{array}{l}6.87 \\
(3.90)\end{array}$ & 0.080 & $\begin{array}{l}12.68 \\
(4.23)\end{array}$ & 0.003 & $\begin{array}{l}12.39 \\
(5.83)\end{array}$ & 0.035 & $\begin{array}{l}14.07 \\
(6.00)\end{array}$ & 0.020 \\
\hline $\begin{array}{l}15 \text { weeks } \\
\text { (m3) }\end{array}$ & $\begin{array}{l}6.37 \\
(3.89)\end{array}$ & 0.103 & $\begin{array}{l}6.42 \\
(3.75)\end{array}$ & 0.089 & $\begin{array}{l}7.60 \\
(4.02)\end{array}$ & 0.061 & $\begin{array}{l}14.79 \\
(5.93)\end{array}$ & 0.014 & $\begin{array}{l}15.42 \\
(5.95)\end{array}$ & 0.011 \\
\hline $\begin{array}{l}26 \text { weeks } \\
\text { (m4) }\end{array}$ & $\begin{array}{l}3.59 \\
(3.89)\end{array}$ & 0.357 & $\begin{array}{l}3.61 \\
(3.75)\end{array}$ & 0.337 & $\begin{array}{l}4.82 \\
(4.02)\end{array}$ & 0.233 & $\begin{array}{l}4.31 \\
(5.69)\end{array}$ & 0.450 & $\begin{array}{l}5.29 \\
(5.75)\end{array}$ & 0.359 \\
\hline $\begin{array}{l}\text { external } \\
\text { conditions } \\
\text { (ext) }\end{array}$ & & & $\begin{array}{l}-0.23 \\
(0.06)\end{array}$ & $\begin{array}{l}<.001 \\
0.00\end{array}$ & & & $\begin{array}{l}-0.14 \\
(0.09)\end{array}$ & 0.126 & $\begin{array}{l}-0.15 \\
(0.09)\end{array}$ & 0.108 \\
\hline summer & & & & & $\begin{array}{l}-2.78 \\
(2.39)\end{array}$ & 0.247 & & & $\begin{array}{l}-2.62 \\
(2.31)\end{array}$ & 0.257 \\
\hline $\mathrm{m} 2$ * ext & & & & & & & $\begin{array}{l}-0.26 \\
(0.24)\end{array}$ & 0.275 & $\begin{array}{l}-0.26 \\
(0.24)\end{array}$ & 0.279 \\
\hline $\mathrm{m} 3$ * ext & & & & & & & $\begin{array}{l}-0.26 \\
(0.14)\end{array}$ & 0.073 & $\begin{array}{l}-0.24 \\
(0.14)\end{array}$ & 0.094 \\
\hline $\mathrm{m} 4$ * ext & & & & & & & $\begin{array}{l}-0.02 \\
(0.13)\end{array}$ & 0.892 & $\begin{array}{l}-0.01 \\
(0.13)\end{array}$ & 0.926 \\
\hline Observations & 215 & & 215 & & 215 & & 215 & & 215 & \\
\hline$R^{2} /$ adj. $R^{2}$ & $0.405 /$ & 0.179 & 0.450 & 0.236 & 0.410 & 0.181 & 0.467 & 0.244 & 0.471 & 0.246 \\
\hline
\end{tabular}

The course of well-being depends on the development of external conditions. Figure 2 shows the course of well-being for ext $=0, e x t=25$ and ext $=50$ points: If the external conditions become less favorable over time, then the described positive effects of well-being become smaller. However, a drop below the initial level is 
prevented even if the external conditions deteriorate significantly (ext $=50)$. It is striking that the long-term measurement point (26 weeks) is independent of the development of the external conditions.

Table 2 shows the gradual model development. Model 1 contains only the four measurement time points. An improvement of the model fit is achieved by including the external conditions as a main effect (model 2 ) and additionally as an interaction effect (model 4). The period effect "summer" is not significant (model 3 and model 5). However, it is significant in terms of content and also marginally improves the model fit from model 4 to model 5 .

\section{Secondary outcome measures}

The baseline level of the secondary outcome measures is shown in Table 1. For each outcome measure, a separate model was calculated with the same operationalization as for well-being (model 5 in Table 2). In terms of direction the attitude-related effects are in line with expectations, but smaller compared to the primary outcome (see Fig. 3). The intervention significantly promotes institutional support and acceptance of the care situation after 26 weeks. However, it has no influence on subjective burden and social support. The intervention significantly promotes recreational behavior over the total observation period (see Fig. 4). No intensity changes are observed with regard to care-related behavior.

\section{Discussion}

In the present study, the effect of a legally funded, one-week health program on the well-being of participating caregiving parents as well as determinant attitudes and behaviors was determined. For this, we used a quasiexperimental design and FE panel regressions.

The initially very low level of well-being is noteworthy. The mean norm score in Germany for women aged $41-60$ years is 69.2 points $(S D=18.4)$ and 64.4 points $(S D=20.9)$ for those aged 61 years and older. The IG score is very significantly lower. Indirectly, the instrument can be used to determine the proportion of individuals with clinically relevant depressive symptoms, which at the start of the intervention is 70 percent in the IG and even slightly higher in the CG. The norm values are significantly lower, at 18 percent for women aged 41-60 and 26 percent for those aged 61 and older (Brähler et al. 2007). For participants in the original SVLFG offer without target group differentiation, the proportion was 50 percent (Hetzel et al. 2016). Even if generalizability is limited as a result of self-selection, this underlines the need for support and relief services specifically for caregiving parents.

The positive initial effect is impressive in magnitude and at the same time an expression of the participants' high need for recreation. This can also be observed in the case of recreational vacations (de Bloom et al. 2013). However, the recovery level quickly returns to the initial level (there already after one week). In the present intervention, the initial effect is also reduced, but it remains significantly above the initial level until 15 weeks after the event and only returns to the initial level after about 26 weeks.

This trajectory is similar to findings in conceptually similar home care interventions for older persons in need of care (Hetzel et al. 2016, 2017). Clues to the underlying mechanism of action are provided by the effects of the secondary outcome measures, which were selected based on stress and behavioral theory. The 
intervention was shown to promote acceptance of the caregiving situation, institutional support, and recreational behaviors. These are likely to determine well-being. Subjective stress and care-related behavior did not change. This is likely to be based on the fact that the care situations have existed since birth or for many years and therefore the care-related support services are likely to be largely optimized. In addition, there is substantial prior experience.

Regression to the mean is unlikely to fully explain the initial effect and the further course of well-being. This statistical effect states that individuals with extreme values - in this case, extremely low well-being scores will inevitably be closer to the mean again at a later measurement, even without intervention and provided that chance has an influence on well-being. This is contrasted by the high acceptance ratings of the IG and the reported subjective benefits at the end of the intervention (not shown here).

The decrease in the initial effect with increasing time can be partially explained. It is possible that participants have become accustomed to the new higher level of well-being, so that the effect then levels off again toward the initial level. An example of this is the effect of salary increases on job satisfaction, which lasts only a short time (Judge et al. 2010). This is related to response shift - the change in the valuation background for a personally significant concept. For example, subjective well-being might be evaluated differently after the intervention than before as a result of peer exchange. Indirect measures of change, i.e., comparing two measurement time points, would thus be biased. Thus, it could be that there are indeed successes in subjective well-being but that they are not detectable by response shift in change measurement. However, methodological approaches to control this phenomenon require larger numbers of cases (Verdam et al. 2016).

Surprisingly, the level of well-being after about 26 weeks is independent of the external conditions. According to the theoretical model, a drop below the initial level would have been expected with increasing stress. The fact that this is not the case is probably due to the fact that the participants learned coping strategies during the intervention that are particularly effective in the case of increasing stress and thus prevent a drop in wellbeing below the initial level. This is supported by the findings described for the secondary outcome measures. Empirically, this would require between-analyses. In view of the selection bias and the small number of cases, this was not done.

Because of the very high initial burden, which indicates a therapeutic need, the reach of a preventive and selective intervention such as the present one is quite considerable. Qualitative feedback from participants indicates that participation contributed to an increase in openness to psychological help and that psychological help was sought in individual cases. This is probably mainly due to the low-threshold involvement of a psychologist in the weeklong program.

Panel data combined with FE panel regression mitigate the problem of unobserved heterogeneity by using only the within-variance to estimate causal effects of an event. However, if the within-variance is not exogenous, these estimators may also be biased. According to Wooldrige (2010), there are three sources of this. (1) The outcome measure could be affected by time-varying heterogeneity, i.e., well-being could have changed because of grief due to the death of a close person, for example. A possible intervention effect would thus be masked. Such effects were controlled for in the model via changes in external conditions as

Page $12 / 20$ 
well as the summer period - sufficiently so, in our view. (2) Reverse causality could be present if, for example, higher well-being levels or rising well-being curves lead to a higher probability of participating in the intervention. As a result, well-being effects would be erroneously identified as intervention effects. The second before measurement time point adequately controls for selection-on-level, i.e., level differences in well-being. The reasons described for the omissions of the before-measurement time points are due to organizational reasons and are likely to be unsystematic. Selection-on-slope, i.e., slope differences, could be controlled (Rüttenauer and Ludwig 2020) but would have required additional before-measurement time points. This means that some of the intervention effects could be due to slope differences in well-being-if rising well-being curves were instrumental in enrolling in the intervention. Although there is no evidence for this, this possible bias is not controlled for. (3) Finally, measurement error could be present, but we consider this to be of secondary importance given the use of proven measurement instruments.

It should be emphasized that ATT (average treatment effect on the treated) estimators were determined here. This means that only the individuals in the IG contributed to the estimator and the results only apply to these individuals. Individuals who did not participate in the intervention would perhaps show quite different effects (Brüderl and Ludwig 2015).

Last but not least, the small sample size is limiting. The confidence intervals are relatively large - for example, the last measurement point of well-being and subjective burden - could be statistically significant in larger samples - and the model complexity must remain low (no effect heterogeneity, age and cohort effects). An increase in the number of cases would be desirable, ideally also outside the green sector. For the described design limitations, a randomized controlled trial would be necessary.

\section{Declarations}

Funding: This work was supported by the Bayerisches Staatsministerium für Gesundheit und Pflege (Vl6/33442/0/17).

Conflict of interests: The authors declare that there is no conflict of interests.

Ethics approval: The Ethical Committee of the German Sport University Cologne approved the study protocol (Nr. 066/2018).

Informed consent: Informed consent was obtained from all participants included in the study.

Consent for publication: Not applicable

Availability of data and material: Not applicable

Code availability: Not applicable

Authors' contributions: Not applicable

\section{References}


Ausserhofer D, Mantovan F, Pirhofer R et al (2009) The burden of parents caring for their children and adolescents with severe disabilities in South Tyrol. Pflege 22:184-195. https://doi.org/10.1024/10125302.22.3.184

Barre F, Epping J (2018) Changes in the use of health insurance services before and after a father-child measure. Gesundheitswesen 80:1048-1054. https://doi.org/10.1055/s-0043-104214

Bech P, Olsen RL, Kjoller M et al (2003) Measuring well-being rather than the absence of distress symptoms: a comparison of the SF-36 Mental Health subscale and the WHO-Five Well-Being Scale. Int J Methods Psychiatr Res 12:85-91. https://doi.org/10.1002/mpr.145

Bech P (2012) Subjective positive well-being. World Psychiatry 11:105106. https://doi.org/10.1016/j.wpsyc.2012.05.021

Berglund E, Lytsy P, Westerling R (2015) Health and wellbeing in informal caregivers and non-caregivers: a comparative cross-sectional study of the Swedish general population. Health Qual Life Outcomes 13:109. https://doi.org/10.1186/s12955-015-0309-2

BMG (2020) Soziale Pflegeversicherung Leistungsempfänger nach Altersgruppen und Pflegegraden am 31.12.2019, https://www.bundesgesundheitsministerium.de/themen/pflege/pflegeversicherung-zahlen-undfakten.html (accessed 05 January 2021)

Brähler E, Mühlan H, Albani C et al (2007) Testing and standardization of the German version of the EUROHIS-QOL and WHO-5 quality-of life-indices. Diagnostica 53:83-96. https://doi.org/10.1026/00121924.53.2.83

Brehaut JC, Garner RE, Miller AR et al (2011) Changes Over Time in the Health of Caregivers of Children With Health Problems: Growth-Curve Findings From a 10-Year Canadian Population-Based Study. Am J Public Health 101(12):2308-16. https://doi.org/10.2105/AJPH.2011.300298

Brüderl J, Ludwig V (2015) Fixed-effects panel regression. In: Best H, Wolf C, editors. The Sage handbook of regression analysis and causal inference. Los Angeles et al: Sage, pp. 327-357.

Calvo-Perxas L, Vilalta-Franch J, Litwin $\mathrm{H}$ et al (2018) What seems to matter in public policy and the health of informal caregivers? A cross-sectional study in 12 European countries. PLoS ONE 13(3),e0194232. https://doi.org/10.1371/journal.pone.0194232.

Cantwell-Bartl AM, Tibballs J (2015) Psychosocial responses of parents to their infant's diagnosis of hypoplastic left heart syndrome. Cardiol Young 25:1065-73. https://doi.org/10.1017/S1047951114001590

Clark MC, Diamond PM (2010) Depression in family caregivers of elders: a theoretical model of caregiver burden, sociotropy, and autonomy. Res Nurs Health 33:20-34. https://doi.org/10.1002/nur.20358

Cousino MK, Hazen RA (2013) Parenting stress among caregivers of children with chronic illness: a systematic review. J Pediatr Psychol 38:809-28. https://doi.org/10.1093/jpepsy/jst049 
Croissant Y, Millo G (2008) Panel data econometrics in R: the plm package. J Stat Software 27:151. https://doi.org/10.18637/jss.v027.i02

de Bloom J, Geurts SAE, Kompier MAJ (2013) Vacation (after-) effects on employee health and well-being, and the role of vacation activities, experiences and sleep. J Happiness Stud 14:613-633. https://doi.org/10.1007/s10902-012-9345-3

Dehn LB, Korn-Merker E, Pfäfflin M et al (2014) The impact on family scale: psychometric analysis of long and short forms in parents of children with epilepsy. Epilepsy Behav 32:21-6.

https://doi.org/10.1016/j.yebeh.2013.12.030

Dlugosch GE, Mücke M (2006) „Pflegen und sich pflegen lassen“ - Evaluation eines Seminarangebotes für pflegende Angehörige. In: Loidl-Keil R, Laskowski W, Evaluationen im Gesundheitswesen. München: Rainer Hampp, pp. 279-329 [in German]

Harris EC, D'Angelo S, Syddall HE et al (2020) Relationships between informal caregiving, health and work in the Health and Employment After Fifty study, England. Eur J Public Health 30(4):799-806. https://doi.org/10.1093/eurpub/ckaa078

Hetzel C, Alles T, Froböse I (2019) Berlin inventory of caregivers' burden with dementia patients (BIZA-D-PV) also for informal caregivers of non-dementia patients? Diagnostica 65:153-166. https://doi.org/10.1026/0012-1924/a000221

Hetzel C, Alles T, Mozdzanowski M (2017) "Mach mal PAUSE vom Pflegealltag" - Konzept und Evaluation eines Interventionsprogramms zur Förderung von guter Pflege und Gesundheit bei pflegenden Angehörigen. Siegburg: Asgard [in German]

Hetzel C, Baumann R, Diekmann J, Froböse I (2018) Description of a multidimensional health program for informal caregivers. Gesundheitswesen 80(S02):S51-S56. https://doi.org/10.1055/s-0042-112814

Hetzel C, Opfermann-Kersten M, Holzer M (2016) Informal caregivers' subjective well-being after a training and recreation week: multilevel models for longitudinal data. Z Gesundheitspsychol 24:1328. https://doi.org/10.1026/0943-8149/a000155

Hetzel C. (2020). Häusliche Pflege im grünen Sektor - Daten der Pflegestatistik. Soziale Sicherheit in der Landwirtschaft, 2:23-28 [in German]

Judge TA, Piccolo RF, Podsakoff NP et al (2010) The relationship between pay and job satisfaction: A metaanalysis of the literature. J Vocat Behav 77:157-167. https://doi.org/10.1016/j.jvb.2010.04.002

Kelly MP, Barker M (2016) Why is changing health-related behaviour so difficult? Public Health 136: 109116. https://doi.org/10.1016/j.puhe.2016.03.030

Lefranc A, Pérol D, Plantier M et al (2017) Assessment of informal caregiver's needs by self-administered instruments: a literature review. Eur J Public Health 27(5):796-801. https://doi.org/10.1093/eurpub/ckx103 
Maguire R, Hanly P, Maguire P (2019) Beyond care burden: associations between positive psychological appraisals and well-being among informal caregivers in Europe. Qual Life Res 28:2135-2146. https://doi.org/10.1007/s11136-019-02122-y

Mauz E, Lange M, Houben R et al (2019) Cohort profile: KiGGS cohort longitudinal study on the health of children, adolescents and young adults in Germany. Int J Epidemiol 49:375-375k. https://doi.org/10.1093/ije/dyz231

Michie S, Ashford S, Sniehotta F et al (2011) A refined taxonomy of behaviour change techniques to help people change their physical activity and healthy eating behaviours: the CALO-RE taxonomy. Psychol Health 26:1479-1498. https://doi.org/10.1080/08870446.2010.540664

Nehring I, Riedel C, Baghi L et al (2015) Psychosocial situation of families with chronically ill children: a survey of parent initiatives. Gesundheitswesen 77(2):102-7. https://doi.org/10.1055/s-0034-1372573

Pearlin LI, Mullan JT, Semple SJ et al (1990) Caregiving and the stress process: an overview of concepts and their measures. Gerontologist 30:583-594. https://doi.org/10.1093/geront/30.5.583

Prochaska JO, Velicer WF, Rossi JS et al (1994) Stages of change and decisional balance for 12 problem behaviors. Health Psychol 13(1):39-46. https://doi.org/10.1037//0278-6133.13.1.39

Rothgang H, Müller R, Runte R, Unger R (2017) BARMER Pflegereport 2017. Berlin, Wuppertal: BARMER Gesundheitsanalyse

Rüttenauer T, Ludwig V (2020) Fixed effects individual slopes: accounting and testing for heterogeneous effects in panel data or other multilevel models. Sociol Methods Res. https://doi.org/10.1177/0049124120926211.

Seliner B, Latal B, Spirig R (2016) 2016 When children with profound multiple disabilities are hospitalized: A cross-sectional survey of parental burden of care, quality of life of parents and their hospitalized children, and satisfaction with family-centered care. J Spec Pediatr Nurs 21:147-157. https://doi.org/10/10.1111/jspn.12150

Sörensen S, Duberstein P, Gill D et al (2006) Dementia care: mental health effects, intervention strategies, and clinical implications. Lancet Neurol 5:961-973. https://doi.org/10.1016/S1474-4422(06)70599-3

Topp CW, Østergaard SD, Søndergaard S et al (2015) The WHO-5 Well-Being Index: a systematic review of the literature. Psychother Psychosom 84:167-176. https://doi.org/10.1159/000376585

Verbakel E, Tamlagsrønning S, Winstone L et al (2017) Informal care in Europe: findings from the European Social Survey (2014) special module on the social determinants of health. Eur J Public Health 27(suppl_1):90-95. https://doi.org/10.1093/eurpub/ckw229

Verdam MGE, Oort FJ, Sprangers MAG (2016) Using structural equation modeling to detect response shifts and true change in discrete variables: an application to the items of the SF-36. Qual Life Res 25:1361- 
Vonneilich N, Lüdecke D, Kofahl C (2016) The impact of care on family and health-related quality of life of parents with chronically ill and disabled children 38:761-

767. https://doi.org/10.3109/09638288.2015.1060267.

Wooldridge J. (2010) The econometrics of cross-section and panel data. Cambridge: MIT Press

\section{Figures}

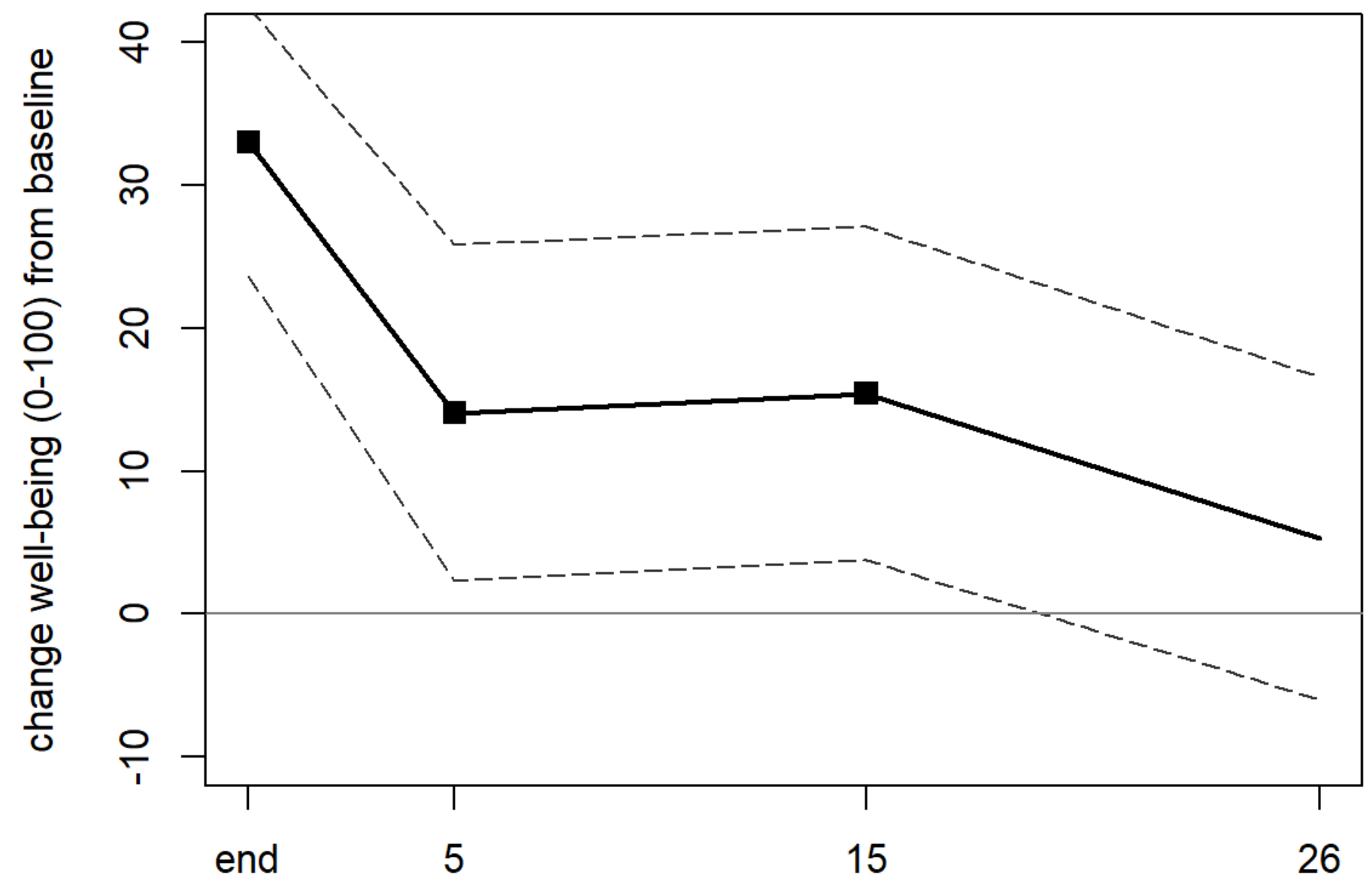

weeks after intervention

Figure 1

Development of well-being in stable external conditions. shown are the coefficients b (filled/unfilled points for $p<0.05 / p<0.10$ ) and the $95 \%$ confidence interval (dashed line) from the fixed effects panel regression (model 


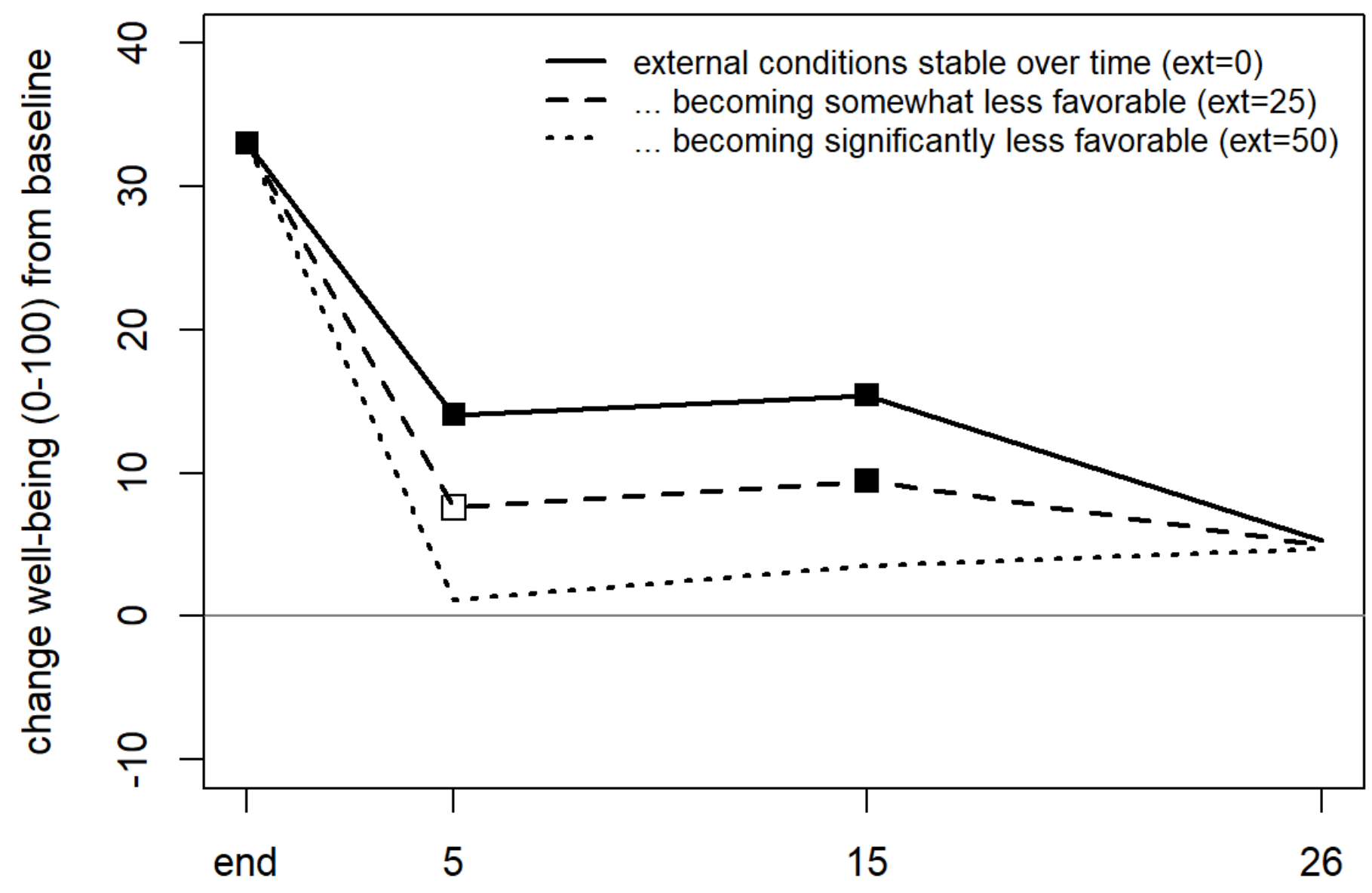

weeks after intervention

Figure 2

Development of well-being for different trajectories of the external conditions. shown are the coefficients $b$ (filled/unfilled points for $p<0.05 / p<0.10$ ) from the fixed effects panel regression (model 5 for different trajectories of the external conditions). 


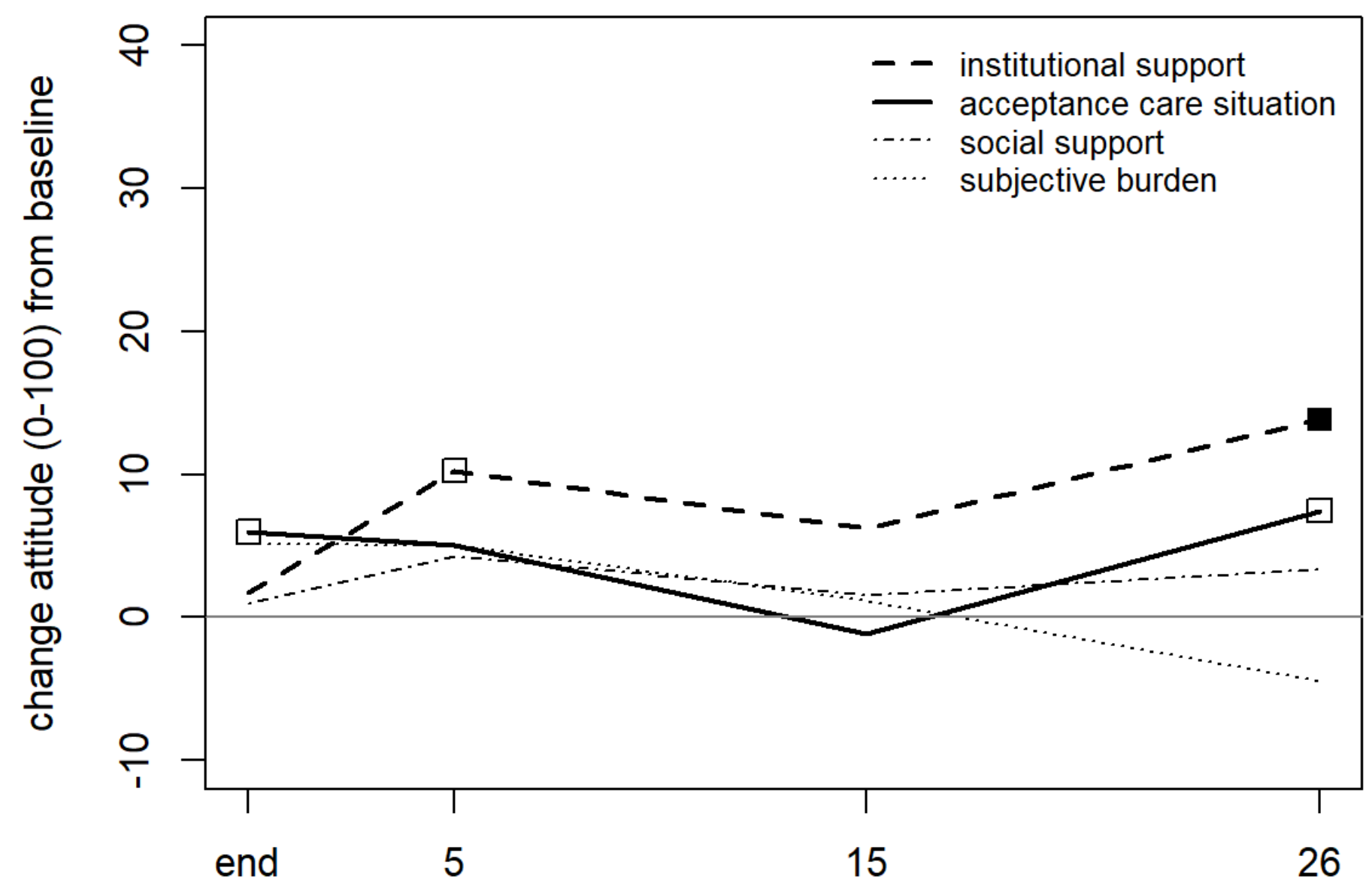

weeks after intervention

\section{Figure 3}

Development of attitudes under stable external conditions. Shown are the coefficients b (filled/unfilled points for $p<0.05 / p<0.10$ ) from the fixed effects panel regression (operationalization as model 5 for stable external conditions with ext=0). The initial effect was only surveyed for "acceptance care situation". This did not make sense for the other outcome measures. Therefore, the values from "start of intervention" were used for "end" in order to be able to evaluate in the time series. 


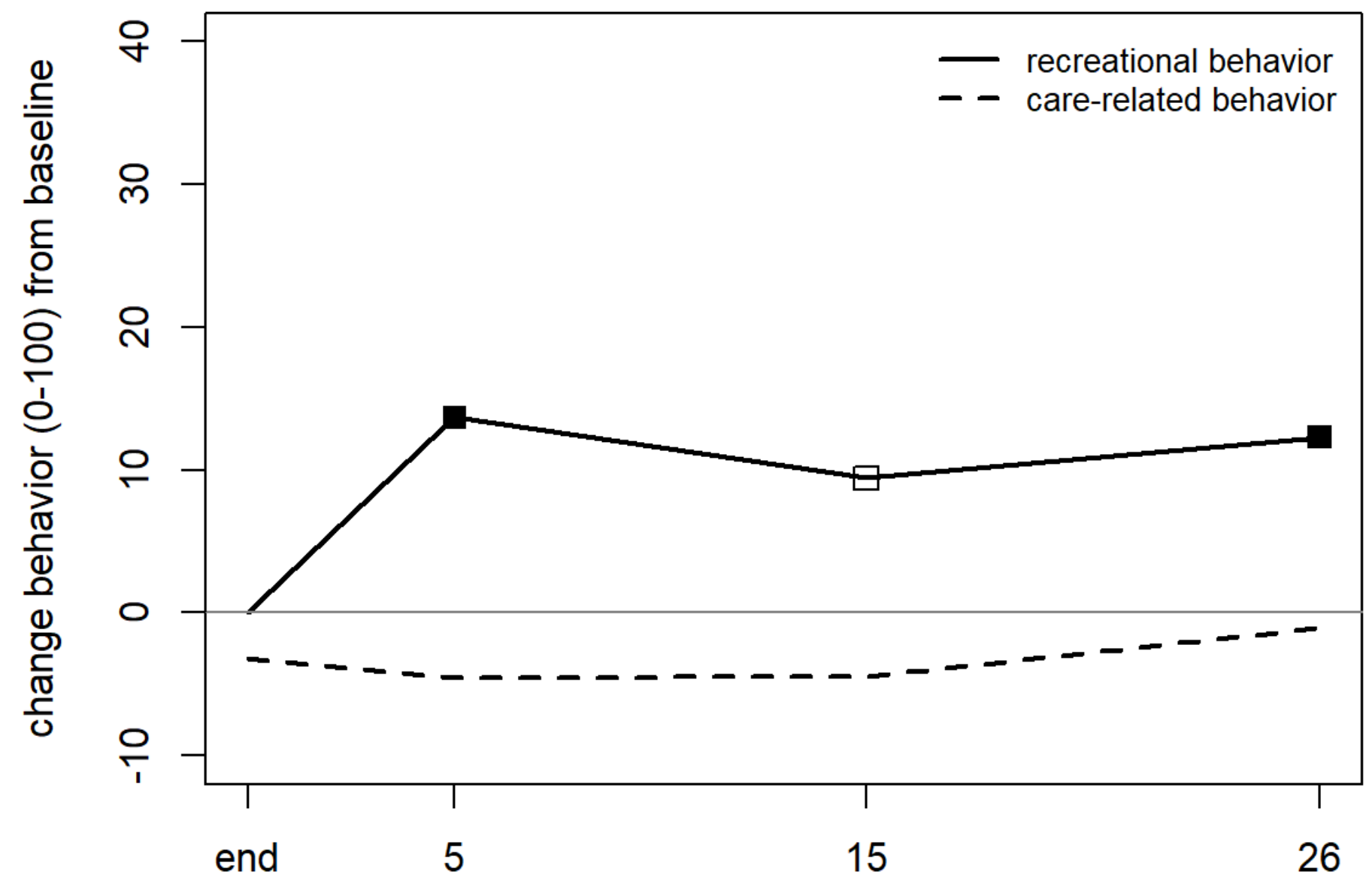

weeks after intervention

\section{Figure 4}

Development of behavior under stable external conditions. Shown are the coefficients $b$ (filled/unfilled points for $p<0.05 / p<0.10$ ) from the fixed effects panel regression (operationalization as model 5 for stable external conditions with ext=0). The initial effect was only surveyed for "acceptance care situation". This did not make sense for the other outcome measures. Therefore, the values from "start of intervention" were used for "end" in order to be able to evaluate in the time series. 